\title{
Development of Phonemic Distinction in Japanese Preschool Children
}

\author{
Eiko Tamashige $^{a}$ Noriko Nishizawa $^{b}$ Hisashi Itoda ${ }^{c}$ Satoko Kasai ${ }^{d}$ \\ Hiroharu H. Igawa ${ }^{e}$ Satoshi Fukuda ${ }^{d}$ \\ ${ }^{a}$ Hokkaido Rehabilitation Counseling Center for the Handicapped, Sapporo, ${ }^{b}$ Department of Communication \\ Disorders, School of Psychological Sciences, Health Sciences University of Hokkaido, Sapporo, 'Department of \\ Early Childhood Education, Nayoro City College, Nayoro, d Department of Otolaryngology, Head and Neck Surgery, \\ Graduate School of Medicine, Hokkaido University, Sapporo, and ${ }^{\mathrm{H}}$ Hair Regenerative Medical Science Research \\ Institute, Tokyo, Japan
}

\section{Key Words}

Phonemic distinction · Japanese children · Speech sound perception

\begin{abstract}
The literature suggests that, within several months of birth, infants develop the ability to distinguish between different speech sounds. However, the time frame for discrimination of a specific phonological system remains unclear. In order to clarify this, the discrimination responses of 211 preschool children were examined. The test battery consisted of 16 pairs of Japanese words, of which each pair contained distinctive phonemes in the initial syllables only. Test stimuli were presented in 2 ways: one as a whole test word and the other as only the initial syllable, which contained the target phoneme. When the test stimuli were whole words, correct discrimination exceeded $60 \%$ for test pairs in age groups older than 2:06-2:11 chronological age (years:months). However, when initial syllables were used, correct discrimination only exceeded $60 \%$ in age groups older than 3:06-3:11. Phonemic distinction within syllables seems to be established during early preschool age in Japanese children.
\end{abstract}

Copyright $\odot 2008$ S. Karger AG, Basel

\section{Introduction}

Previous research on the development of speech sound perception has revealed that young infants respond to speech sounds according to categories that serve as the basis for adult phonemic categories [1]. Eimas et al. [2] found that 1 - and 4-month-old infants were able to discriminate acoustic cues within synthetic sounds that underlie the adult phonemic distinction between voiced and voiceless stop consonants. Werker et al. [1] reported that 7-month-old infants discriminated many speech sounds according to phonemic category regardless of language exposure, whereas adults may have difficulty in discriminating nonnative linguistic contrasts. Hayashi et al. [3, 4] reported that infants younger than 1 year old demonstrated a developmental shift in their preference of native or prosodically natural speech stimuli to nonnative or prosodically unnatural speech. These studies revealed that infants' perception of speech sounds matures selectively according to their native language from a very early age; however, they did not clarify whether the infants categorize speech sounds in the same way as adults extract and identify the phonemes in their native phonological system.

\section{KARGER}

Fax +41613061234 E-Mail karger@karger.ch www.karger.com
Eiko Tamashige

Hokkaido Rehabilitation Counseling Center for the Handicapped

2-1-1 Maruyama-nishi-machi, Chuoh-ku

Sapporo 0640944 (Japan)

Tel. +81 11613 5445, Fax +81 11613 4893, E-Mail tamashige.eiko@pref.hokkaido.lg.jp 
Table 1. Number of subjects in each age group

\begin{tabular}{|c|c|c|c|c|c|c|c|}
\hline \multicolumn{7}{|c|}{ Age groups } & \multirow[t]{2}{*}{ Total } \\
\hline $2: 6-2: 11$ & $3: 0-3: 5$ & $3: 6-3: 11$ & $4: 0-4: 5$ & $4: 6-4: 11$ & $5: 0-5: 5$ & $5: 6-5: 11$ & \\
\hline 6 & 29 & 36 & 54 & 36 & 20 & 30 & 211 \\
\hline
\end{tabular}

There is an accumulation of knowledge regarding the development of phonemic distinction in English-speaking children. Nittrouer [5] reported that 3-year-old children are not as sensitive to changes in acoustic cues as adults are. Using altered human speech to measure discrimination of speech sounds in word contexts, Carpenter [6] found that discrimination on the basis of spectral cues (such as formant transition) was satisfactory in 4year-old subjects, but that discrimination of temporal cues (such as voice onset time) improved between 4 and 6 years of age. Wolf [7] suggested that discrimination performance of kindergarten (mean age: 5:04; years: months) and low grade (mean age: 7:05) elementary school children in the categorization of contrasts along a voice onset time continuum was comparable to the performance of adults in other studies using the same stimuli. Treiman et al. [8] reported that the phonemic recognition performance of 5-year-old children was better with stop than with fricative consonants, although the difference was not statistically significant. The percentage of correct responses exceeded $70 \%$ for both target sounds.

From these previous studies, we can predict that children's phonological system is perceptually established and specified for their native language between 4 and 5 years of age. However, not much is known about the exact time frame of phonemic distinction concerning numerous perceptual cues and distinctive features. In particular, we have few reports on phonemic distinction development in Japanese language speakers. The purpose of this study was to establish the time frame for discrimination of the specific phonological system of Japanese-speaking children.

\section{Method}

Subjects

A total of 211 preschool children between the ages of 2:06 and 5:11 participated in this study (table 1). The subjects were divided into 7 groups according to age. All subjects were reported by their mother to be developing normally. The aims and methods of this
Table 2. Stimulus words

Distinctive feature

Voicing

/paN/ vs. /baN/, /teNki/ vs. /deNki/, /karasu/ vs. /garasu/

3

(bread vs. bang, weather vs. electric light, crow vs. glass)

Place of articulation

/tobu/ vs. /kobu/

1

(to fly vs. lump)

Nasalization

/macu/ vs. /bacu/, /neru/ vs. /deru/

2

(pine tree vs. X mark, to sleep vs. to come out)

Manner of articulation

/puu/ vs. /huu/, /tora/ vs. /sora/

2

(Winnie the Pooh vs. blowing sound on hot tea, tiger vs. sky)

Existence of a consonant

/kame/ vs. /ame/, /paN/ vs. /aN/, /cume/ vs. /ume/, /toru/

5

vs. /oru/, /kuma/ vs. /uma/

(turtle vs. rain, bread vs. bean jam, finger nail vs. pickled plum,

to take away vs. to break, bear vs. horse)

Two distinctive features

/nori/ vs. /tori/, /cjuu/ vs. /kjuu/, /curi/ vs. /kuri/

3

(paste vs. bird, squeak vs. nine, fishing vs. chestnut)

Total

16

study were explained to the parents of each subject. The test was performed with the voluntary consent from each parent for their child's participation in the experiment.

Stimulus Words

The Phonemic Discrimination Test consisted of 16 pairs of Japanese words, each pair of which contained distinctive phonemes in the initial syllable of the word (table 2). We chose 31 words that are commonly known to young children. Among these test words, the word /paN/ (bread) was used in 2 test pairs. Consequently, the number of the test pairs was 16 .

The knowledge of the test words was previously assessed in individual subjects. Age groups 3:06-3:11 and older could spontaneously say more than $80 \%$ of the words on the list. If the child did not know the target word, the experimenter taught the name of the word to the child prior to the Phonemic Discrimination 
Table 3. Percentage of correct responses in the word discrimination task

\begin{tabular}{lllllll}
\hline Age group & \multicolumn{5}{l}{ Distinctive feature, $\%$} \\
\cline { 2 - 6 } & voicing & $\begin{array}{l}\text { place of } \\
\text { articulation }\end{array}$ & nasalization & $\begin{array}{c}\text { manner of } \\
\text { articulation }\end{array}$ & $\begin{array}{l}\text { existence of } \\
\text { a consonant }\end{array}$ & $\begin{array}{c}\text { 2 distinc- } \\
\text { tive features }\end{array}$ \\
\hline 2:6-2:11 & 76.0 & 83.3 & 56.3 & 87.5 & 84.8 & 66.7 \\
$3: 0-3: 5$ & 83.3 & 62.1 & 75.0 & 82.5 & 86.8 & 80.5 \\
$3: 6-3: 11$ & 84.9 & 91.7 & 87.5 & 91.7 & 97.6 & 94.4 \\
$4: 0-4: 5$ & 93.7 & 92.6 & 100.0 & 98.0 & 98.4 & 95.7 \\
$4: 6-4: 11$ & 93.5 & 97.2 & 100.0 & 96.4 & 99.4 & 96.3 \\
$5: 0-5: 5$ & 100.0 & 100.0 & 100.0 & 100.0 & 100.0 & 100.0 \\
$5: 6-5: 11$ & 100.0 & 96.7 & 100.0 & 100.0 & 100.0 & 100.0 \\
\hline
\end{tabular}

Table 4. Percentage of correct responses in the syllable discrimination task

\begin{tabular}{lllllll}
\hline Age group & \multicolumn{5}{l}{ Distinctive feature, $\%$} & \\
\cline { 2 - 6 } & voicing & $\begin{array}{l}\text { place of } \\
\text { articulation }\end{array}$ & nasalization & $\begin{array}{l}\text { manner of } \\
\text { articulation }\end{array}$ & $\begin{array}{l}\text { existence of } \\
\text { a consonant }\end{array}$ & $\begin{array}{l}2 \text { distinc- } \\
\text { tive features }\end{array}$ \\
\hline $2: 6-2: 11$ & 28.0 & 33.3 & 31.3 & 50.0 & 39.4 & 33.3 \\
$3: 0-3: 5$ & 36.7 & 20.7 & 37.5 & 55.0 & 53.7 & 56.3 \\
$3: 6-3: 11$ & 53.4 & 61.1 & 70.8 & 68.8 & 80.5 & 70.4 \\
$4: 0-4: 5$ & 64.6 & 70.4 & 80.0 & 86.0 & 78.8 & 76.5 \\
$4: 6-4: 11$ & 69.6 & 72.2 & 89.3 & 82.1 & 89.5 & 85.2 \\
$5: 0-5: 5$ & 87.5 & 90.0 & 100.0 & 100.0 & 97.7 & 96.7 \\
$5: 6-5: 11$ & 90.5 & 93.3 & 100.0 & 100.0 & 93.9 & 95.6 \\
\hline
\end{tabular}

Test. The distinctive features used to contrast the test words were: (1) voicing in 3 pairs; (2) place of articulation in 1 pair; (3) nasalization in 2 pairs; (4) manner of articulation in 2 pairs; (5) existence of an initial consonant in 5 pairs. Further, 2 distinctive features were included simultaneously in 3 pairs of test words. These distinctive features were based on the traditional features as defined by Ladefoged [9].

\section{Procedure}

The Phonemic Discrimination Test consisted of 2 experimental tasks. The first task was word discrimination. The experimenter showed a pair of pictures representing the test words, and then spoke the word representing 1 of the pictures. The child was encouraged to respond by pointing to the matching picture. The trials were done randomly with each pair of test words appearing at least 4 times. If the child pointed to the wrong picture 1 or more times, he/she was regarded as unable to discriminate the word. The second task was syllable discrimination. The procedure of this task was similar to that of word discrimination. The only difference was that the experimenter presented the initial syllable only. Most Japanese syllables consist of $\mathrm{V}$ or CV structures. Thus, we considered the initial syllable of a word to be the minimal phonological unit that could be discriminated phonemically by young Japanese children. Although syllable discrimination does not directly test the subject's phoneme cognition, we consider syllable discrimination to be nearly equivalent to phonemic distinction in the Japanese phonological system. For the second task, it was explained to the child that only the first part of the test word was to be given, and that he/ she had to point to the matching picture. If the child pointed to the wrong picture 1 or more times, he/she was regarded as unable to discriminate the syllable.

\section{Results}

Table 3 shows the percentage of correct responses in the word discrimination task. The correct response rate exceeded 60\% for all test pairs in age groups 3:0-3:05 and older.

Table 4 shows the percentage of correct responses in the syllable discrimination task. The correct response 
rate exceeded $60 \%$ for all test pairs in age groups $4: 0$ 4:05 and older.

Children performed relatively poorly on the voicing trials. An analysis of percentages based on a $\chi^{2}$ analogue of Fisher's exact probability test was then applied to this data. Average performance in the voicing trials was significantly poorer than performance in the existence of consonant trials (3:0-3:05 $\mathrm{p}<0.05,3: 06-3: 11 \mathrm{p}<0.001$, 4:0-4:05 $\mathrm{p}<0.02,4: 06-4: 11 \mathrm{p}<0.001)$, the 2 distinctive features trials $(3: 0-3: 05 \mathrm{p}<0.02,3: 06-3: 11 \mathrm{p}<0.05$, 4:06-4:11 $\mathrm{p}<0.05)$ and the manner of articulation trials $(4: 0-4: 05 \mathrm{p}<0.01)$

Furthermore, average performance in the syllable discrimination task was compared with performance in the word discrimination task for each age group. Average performance in the word discrimination task significantly exceeded performance in the syllable discrimination task for each age group $(2: 06-2: 11 \mathrm{p}<0.001$, 3:0-3:05 $\mathrm{p}<0.001,3: 06-3: 11 \mathrm{p}<0.001,4: 0-4: 05 \mathrm{p}<$ 0.001, 4:06-4:11 $\mathrm{p}<0.001,5: 0-5: 05 \mathrm{p}<0.05,5: 06-5: 11$ $\mathrm{p}<0.001)$.

\section{Discussion}

This study was carried out in an attempt to clarify the time frame for phonemic distinction in Japanese language speakers. In standard developmental tests, the critical ratio is $60 \%$; that is, when the correct response exceeds $60 \%$ in an age group, discrimination is considered to be established for the group. We tested 16 pairs of words, in each pair of which the initial syllables of the words were phonemically distinctive. The distinctive features of the test syllables were categorized into 5 types. The chronological age groups in which the correct discrimination exceeded $60 \%$ for all the test pairs were 3:0 onwards, when the test stimuli were whole words. When only the initial syllables were used, correct discrimination only exceeded $60 \%$ in age groups $3: 06-$ 3:11 and older. The results suggest that syllabic discrimination of phonemes in the Japanese phonological system is established by age 4 years. This finding is consistent with the literature regarding syllabic discrimination in the English language (Nittrouer [5], Wolf [7]).

The literature suggests that phonemic distinction in children develops differently among the numerous phonological features of speech sounds (Carpenter [6]). A large number of tests developed to measure phonemic awareness vary both in the cognitive demands of the tasks that children are asked to perform and in the lin- guistic structure of the items. Because of these differences, it can be difficult to compare performance within and across phonemic awareness tests. In the present experiment, however, the result obtained was consistent with that of Carpenter [6], i.e. that the average performance in the voicing trials was relatively poorer than that in the other patterns. Our result is also consistent with the study by Treiman et al. [8]. They found that preschoolers and kindergartners were more likely to make a mistake when the initial phoneme of the syllable differed from the target only in voicing (e.g. / $t /$ for the target /d/) than when it differed in place of articulation (e.g. /b/ for the target $/ \mathrm{d} /$ ) or in both place and voicing (e.g. $/ \mathrm{p} /$ for the target $/ \mathrm{d} /$ ).

We adopted 2 discrimination tasks, word discrimination and syllable discrimination. Average performance in the word discrimination task significantly exceeded performance in the syllable discrimination task for each age group. This is to say, even when a child was aware that the words of each test pair differed in sound, he/she could not necessarily discriminate the individual distinctive syllables in the words. The time frame for syllabic discrimination in the Japanese phonological system is shown to be later than the time frame of word discrimination. Thus a 3 -year-old child can discriminate a word, though he/she does not know the syllabic structure of the word. The word discrimination strategy may change as a function of development.

\section{Acknowledgment}

The authors thank Ms. Minako Funayama, who is a former head of teaching staff for the Speech-Language Pathology and Audiology Course at the College attached to the National Rehabilitation Center for Persons with Disabilities, for her critical review of this paper. 


\section{References}

$D_{1}$ Werker JF, Gilbert JHV, Humphrey K, Tees RC: Developmental aspects of cross-language speech perception. Child Dev 1981;52: 349-355.

-2 Eimas PD, Siqueland ER, Jusczyk P, Vigorito J: Speech perception in infants. Science 1971; 171:303-306.

3 Hayashi A, Deguchi T, Kiritani S: Response patterns to speech stimuli in the headturn preference procedure for 4- to 11-month-old infants. Jpn J Logop Phoniatr 1996;37:317323.
4 Hayashi A, Deguchi T, Tamekawa Y, Kiritan S: Developmental change in preferential listening responses for prosodic patterns of speech stimuli in 4- to 14-month-olds - perception of prosodic cues to clausal units RIEEC (The Research Institute for the Education of Exceptional Children). Tokyo Gakugei University, 1997, pp 87-94.

5 Nittrouer S: Discriminability and perceptual weighting of some acoustic cues to speech perception by 3-year-olds. J Speech Hear Res 1996;39:278-297.
6 Carpenter RL: Development of acoustic cue discrimination in children. J Commun Disord 1976;9:7-17.

7 Wolf CG: The perception of stop consonants by children. J Exp Child Psychol 1973;16: 318-331.

-8 Treiman R, Broderick V, Tincoff R, Rodriguez K: Children's phonological awareness: confusions between phonemes that differ only in voicing. J Exp Child Psychol 1998;68: $3-21$

9 Ladefoged P: Elements of Acoustic Phonetics. Chicago, University of Chicago Press, 1967. 